\title{
Santo Inácio de Loyola: tradutor
}

\author{
St. Ignatius of Loyola: translator
}

Edgard Leite Ferreira Neto

\section{Resumo}

Este estudo pretende analisar o desenvolvimento da tradição mística católica e o seu conteúdo teológico, considerando-a como continuadora da tradição profética judaica e com ela convergindo enquanto procedimento tradutor de experiências de contato com Deus, através da utilização da imaginação, ou de analogias catafáticas. Analisamos alguns dos principais elementos do pensamento místico e seu desenvolvimento histórico e conceitual, até a emergência da Religio Moderna. Mostramos como a literatura mística encontrou no Cardeal Cinsneros um entusiasta e divulgador. Sua atuação, editorial e acadêmica, criou um importante substrato intelectual na Espanha, fortalecedor da experiência mística. Por fim, discutiremos como Santo Inácio de Loyola recebeu e entendeu tal legado intelectual e abordou alguns de seus temas no âmbito das transformações de seu tempo, sendo, ao mesmo tempo, um experimentador da Eternidade e um produtor de sentidos, um tradutor, expressando a relação íntima com Deus através dos temas da individualidade, da pluralidade do mundo moderno e das quantificações.

Palavras-chave: Jesuítas. Santo Inácio de Loyola. Mística.

\section{Abstract}

This study analyzes the Catholic mystical tradition development and its theological content, considering it as continuer of the Jewish prophetic tradition and its translator aims through the use of imagination, or cataphatics analogies. We analyze the main elements of mystical thought and literature until the emergence of Religio Moderna. We show how the mystical literature 
found in Cardinal Cinsneros an enthusiast and promoter. His performance, editorial and academic, created an important intellectual substrate in Spain, strengthening mystical experiences. Finally, we discuss how St. Ignatius of Loyola got such intellectual legacy and understood some of their issues in the context of modernity, working as a experimenter od Eternity and a producer of meanings, a translator, expressing intimate relationship with God through the themes of individuality, the plurality of the modern world and quantifications.

Keywords: Jesuits. St. Ignatius of Loyola. Mystic.

\section{Introdução: falar profético, falar tradutor}

O falar profético é um falar tradutor. Seu objetivo primeiro é a tradução, para o tempo, de uma dimensão que está fora do tempo: a realidade de Deus. Em si, é histórico, mas sua essência não é entendida como tal. A tradição bíblica assegura a existência de tal dinâmica, e coloca o Profeta entre dois mundos, atuando tanto na vigília quanto na imaginação, no momento e na Eternidade. As narrativas de suas visões são, por isso mesmo, simbólicas, aproximativas, metafóricas. Dependem da inspiração - e imaginação - do Profeta, elas mesmas fruto de uma dinâmica que é tida por própria dele e própria de Deus. E que traduz a tensão decorrente da justaposição do infinito e do finito.

Embora a literatura profética encontre sua matriz no idioma hebraico, considerado, em princípio, como a linguagem comum entre vigília e imaginação, entre homens e Deus, em tempos bíblicos tardios entendia-se que tais narrativas podiam ser traduzidas em aramaico e em grego, o que ampliava esse movimento tradutor para outras dimensões: os idiomas humanos. Onkelos, o mítico tradutor da Bíblia para o aramaico ou os setenta e dois sábios que, no Egito, traduziram a Bíblia para o grego, se relacionavam com uma essência que transcendia as linguagens, e que estava além do próprio hebraico. Os Evangelhos, em grego, também realizaram esse movimento em direção a um idioma oculto, o falado por Jesus, seus apóstolos e o povo judeu da época: o aramaico, Mas promoveram tal processo a partir de um nível interior de significados, traduzindo os elementos da mensagem de Jesus para o grego, a partir de um metatexto que, em princípio, tinha fortes componentes memoriais, mas que era também representação, no campo da imaginação, de eventos reais cuja concretude repousava em essências apenas percebidas na mistura de tempo e Eternidade. 
Refletir sobre esse "falar tradutor", como o descreveu Certeau', e encontrar os mecanismos para desenvolvê-lo, era já uma preocupação em períodos anteriores ao Novo Testamento, pois se percebia que textos proféticos antigos, para além de conterem traduções da Eternidade para a temporalidade, deveriam também ser traduzidos do tempo em que foram escritos para o tempo presente. É o caso de Pesher Habacuc, documento encontrado em Qumran, que continha a tentativa de escribas judeus em entender ao que se refeririam, no momento, aquelas profecias feitas no passado. Considerando a natureza dinâmica da linguagem, mesmo de hebraico para hebraico, continha-se aqui, portanto, uma ação tradutora.

$\mathrm{O}$ entendimento dos complexos mecanismos envolvidos em tal movimento tradutor melhoraram substancialmente, no entanto, com o recurso à filosofia grega, cuja precisão conceitual permitiu elaborar diversas teorias gerais sobre a natureza do contato entre homem e Deus, ou, como passou a ser denominado, a experiência mística, enquanto fundadora da vivência profética. Essa experiência sempre pareceu, entre outras coisas, representar a própria essência do mistério da relação humana com o mundo e com os outros, que é um movimento de tradução, de discernimento. A impressão de que os seres se relacionam realizando entendimentos tradutores subjetivos, eventualmente continha a crença de que tal realidade exprimia uma dimensão mais profunda, que era a da relação do ser com Deus. Nesta alcançava-se o desafio tradutor por excelência: o do sentido da vida.

\section{Elementos da mística}

Uma primeira especulação teórica focada, denominadora e influente, sobre esse movimento interior da alma em direção a Deus, no interior do cristianismo, foi aquela realizada pelo, assim chamado hoje, Pseudo-Dionísio, um pensador do sexto século da era cristã. Foi ele um dos primeiros a introduzir, dentro do cristianismo, conceitos específicos para pensar a dinâmica desse processo de aproximação ao divino, ou de tradução de sua realidade. Religiosos anteriores, como Santo Agostinho e Orígenes, por exemplo, já tinham refletido profundamente sobre esse tipo de experiência, mas Pseudo-Dionísio fundou parâmetros conceituais de grande influência no pensamento teológico.

Entre diversas reflexões, Pseudo-Dionísio defendeu, em sua Teologia

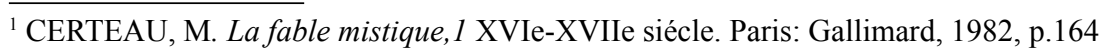


Mística, a existência de dois mecanismos de aproximação a Deus: o apofático, o dito negativo, e o catafático, isto é, o positivo ${ }^{2}$. Ambos complementares, expressariam, no entanto, o reconhecimento conceitual da impossibilidade humana em alcançar a profundidade e grandeza infinitas da essência de Deus e traduzi-la plenamente, de forma racional. Assim, entendeu Pseudo-Dionísio que a experiência mística gravitava entre experimentar o divino em uma perspectiva negativa, ou seja, entendendo-O pelo que Ele não é, na medida em que Ele está além de tudo que conhecemos, e tudo que conhecemos precede dEle mas não é Ele; e uma perspectiva afirmativa, descrevendo-O, por exemplo, como "Bom, Existente, Vivo, Sabedoria, Poder", ou através de seus atributos visíveis, que dEle emanam e que contém algo dEle, de forma analógica. Andrew Louth apontou a fonte filosófica de Pseudo-Dionísio, o filósofo neoplatônico Proclus, que entendia, basicamente, que o movimento apofático sustentava o catafático ${ }^{3}$, isto é, partia-se da impossibilidade para a possibilidade. Assim, toda apreensão de Deus seria essencialmente indireta, e analógica, ou fundamentalmente subjetiva, já que a objetividade não era capaz de realizar sua descrição, expressão ou tradução completa.

Como escreveria, depois, São Tomás de Aquino, "é conveniente que a Escritura sagrada nos proponha as coisas espirituais envoltas em imagens de coisas corpóreas", porque "seria impossível que o raio de luz divina brilhasse para nós se não fosse amortecido com variedade de véus sagrados" ${ }^{4}$. E, em outra oportunidade, "como não podemos ver sua essência chegamos a conhecer seu ser não por seu ser mesmo, senão por seus efeitos", e, adiante: "não é necessário que Deus seja em si mesmo naturalmente conhecido, senão em sua semelhança. E, por conseqüência, é necessário que o homem vá ao conhecimento de Deus raciocinando pelas semelhanças que encontra em seus efeitos". 5

Santo Agostinho, cuja sensibilidade diante da presença do divino possuía grande eloqüência, postulou a existência de três tipos de visão: a do órgão externo (visio corporalis); a interior, da imaginação (visio spiritualis); e a do

\footnotetext{
${ }^{2}$ PSEUDO-DINONYSIUS. "The Mystical Theology": 3. In: The Complete Works. New York: Paulist Press, 1987. Ver também ROREM, P. Pseudo-Dionysius: A Commentary on the Texts and an Introduction to Their Influence. Oxford: Oxford, 1993.

${ }^{3}$ LOUTH, A. "Apophatic and Cataphatic Theology". In: HOLLYWOOD, A. The Cambridge Companion to Christian Mysticism. Cambridge: Cambridge, 2012, p. 140.

${ }^{4}$ AQUINO, S. T. Summa Teologica, vol. I. Madrid: BAC, 1959, p. 277.

${ }^{5}$ AQUINO, S. T. Summa Contra Gentiles, Vol. I. Madrid: B.A.C., 2007, p. 119.
} 
intelecto, o olhar da mente (visio intellectualis). Ele entendeu que a última era superior na aproximação a Deus, considerando a ambiguidade do olhar da imaginação, ou espiritual, e as limitações do corpo ${ }^{6}$. Para ele, portanto, a tradução deveria possuir uma dimensão essencialmente intelectual, superior, que transcendia as limitações das imagens, as reais e as imaginárias.

Mas muitos, no séculos subsequentes, afirmaram, no entanto, como Santo Tomás, que a visão da imaginação podia, sim, propiciar um acesso a Deus e, ao ser traduzida, pela linguagem (pela literatura, pela arte, pela música), permitia construir as necessárias pontes, sempre subjetivas, entre as negações, afirmações e analogias diversas, os "véus sagrados", e Deus. E a literatura bíblica, tanto a hebraica quanto a grega, afirmava, de fato, a todo tempo, o caráter imagético das visões e seu papel tradutor, ou de meio. Tal perspectiva afirmativa sobre o poder da imaginação, como espaço e expressão da mística, foi referendada por São Gregório o Grande (?-604), que defendeu o papel dos olhos do coração (cordis oculis), analisando o caso de São Bento de Nursia (c. 480-547). Demonstrou, então, que um anjo conduziu o religioso ao êxtase e lhe propiciou, através de um olhar interior, a visão de coisas não vistas pelos homens com seu olhar corpóreo, e essas visões nos traziam luzes sobre a realidade de Deus ${ }^{7}$.

A perspectiva do Pseudo-Dionísio, portanto, de propiciar a construção de analogias, ou "véus sagrados", como meio da mística, foi influente, de fato. Mesmo porque a experiência mística, na história do cristianismo, tinha raízes não apenas no antigo profetismo judaico, mas, do ponto de vista cristão, na experiência do monasticismo fundador, que cultivava de diferentes maneiras tal visionarismo. Por exemplo, através da recorrente mentalização de imagens diversas, quando se tratava de propiciar uma profunda experiência espiritual. No Apophthegmata Patrum, texto ligado aos "padres do deserto", ascetas do $\mathrm{V}$ século, conta-se do eremita que, quando rezava, imaginava-se cercado de labaredas de fogo, o que potencializava sua concentração ${ }^{8}$.

É claro que as cautelas de Santo Agostinho sobre a ambiguidade das visões espirituais, da imaginação, não podiam, no entanto, deixar de ser consideradas. Mesmo porque entendia-se que o Mal se insinuava precisamente

${ }^{6}$ WOLLO, L.Z.: "St Augustine on the Soul's Divine Experience": Visio intellectualis and Imago Dei from Book XII of De genesi ad litteram libri XII. Studia Patristica, vol. LXX. Leuven: Peeters, 2013.

${ }^{7}$ FRAETERS, V. "Visio/Vision”. In: HOLLYWOOD, A. op.cit, p. 179.

${ }^{8}$ BURTON-CHRISTIE, D.“Early Monasticism”. In: HOLLYWOOD, A. op.cit., pp. 37-52. 
através da imaginação humana. Donde, primeiro, entender-se que a imagem era, principalmente, um meio para apreensão da realidade divina acessada através das analogias e não o fim em si e, segundo, elaborarem, os místicos, técnicas diversas de discernimento dos espíritos, diakrisis, cujo objetivo era entender o movimento dos pensamentos, em função dos pecados que ali emergiam - e da virtual presença do Mal - e, no sentido de controlar tal corrupção, abrir caminho para a vivência verdadeira de Deus no campo da própria imaginação, ou da visio spiritualis, discernindo claramente o que eram imagens de Deus e as que eram apenas do mundo, o que servia para a aproximação a Deus e o que servia para afastar o homem do seu caminho'. Do ponto de vista institucional, aquelas que marchavam na direção da Igreja e aquelas no caminho das heresias. O tema era antigo e a Bíblia, tanto na tradição do Tanach quanto do Novo Testamento, sempre advertiu contra a presença de falsos profetas.

A construção de sistemas nesse sentido caracterizam a mística medieval. Tomemos, por exemplo, a obra que foi entendida como sendo de São Boaventura, franciscano que doutorou-se com Santo Tomás de Aquino em Paris, em 1257. A ele foram atribuídos muitos textos influentes, de natureza conceitual, fundados na visão de São Francisco de Assis do anjo com seis asas - e na recorrência desse número na Bíblia -, utilizados para sistematizar o processo de elevação espiritual. O objetivo desses textos era entender e estabelecer os processos mentais necessários para que a experiência espiritual interna pudesse se desenvolver de maneira harmoniosa, através de seis etapas. Inseria-se seu esforço na busca de práticas de meditação, meditatio, eficientes. Eles continham uma exposição dos procedimentos corretos para visualizar as imagens do mundo e encontrar nelas as analogias necessárias, isto é, considerando-as como meio, até que se chegasse a um sexto nível de contemplação, quando então cessaria toda possibilidade "de comparação com coisas criadas" alcançada a experiência de Deus.

Em um outro texto a ele atribuído, o Meditationes vitae Christi, o autor explica, no Prólogo, a importância de uma meditação catafática, baseada no imaginário visual, no qual o religioso era convidado a colocar-se, em imaginação, ao lado de Jesus, como "se você estivesse ouvindo tudo com seus próprios ouvidos e vendo tudo com seus próprios olhos, dando a isto toda

\footnotetext{
${ }^{9}$ Idem, ibidem, p. 50.

${ }^{10}$ BONAVENTURE. "The Journey of the Mind to God". In: PETRY, A. Late Medieval Mysticism. Louisville: Westminster John Knox Press, 2006.
} 
resposta mental"11. A visualização de Jesus, e a imagem de sua humanidade, permitia uma interface com algo que estava além da humanidade reconhecida, já que Jesus possuía as duas dimensões. Experiência que abria caminho e colocava em contato dimensões finitas e infinitas do mundo, no campo da imaginação, aqui colocada como instrumento de percepção daquilo que está além da objetividade do mundo.

As mesmas preocupações aplicavam-se à experiência da leitura dos textos bíblicos. Preocupação permanente desde tempos pré-cristãos, e que dizia respeito à tradução de seu significado, uma experiência que podia ser mística, enquanto tradução de alguma coisa que estava além do texto em si e essa "coisa" era o mistério. Tratava-se aqui da Lectio Divina, a leitura inspirada e mística dos textos sagrados. As leituras de Santo Agostinho sempre foram influentes nesse sentido, por exemplo, nas Confissões, a sua célebre interpretação de Genesis I:1-2, do qual extrai a percepção do mistério da Trindade ${ }^{12}$ que era, certamente, fruto de um "olhar intelectual", mas também da sua imaginação inspirada.

Uma longa tradição de textos medievais esteve centrada na exposição de significados maiores contidos nos textos sagrados. Muito influentes foram, por exemplo, os estudos do Abade cisterciense Bernardo de Claraval (10901153), sobre o Cântico dos Cânticos, esse livro enigmático, cuja grandeza mística sempre foi evidente, ainda na época do Segundo Templo de Jerusalém, e que representava, no aspecto central que ali desempenhava o amor, uma analogia da relação entre homem e Deus. Tal texto demonstraria, por excelência, a potencialidade das experiências analógicas na tradução do divino.

Outro texto influente foi o Scala Claustralium, "A escada dos Monges", escrito pelo monge Guigo (Guy),o cartusiano (?-1188?). Nesse livro Guy expôs os métodos da leitura que abririam caminho para a meditação, oração e contemplação, lectio, meditatio, oratio e contemplatio. Numa metáfora de cunho catafático, Guy convidava os leitores a saborear as palavras sagradas como se saboreia a comida, extraindo delas seu sabor e doçura, principalmente através da oração, oratio $^{13}$. O texto de Guy foi traduzido em diversas línguas vernáculas e se tornou um guia seguro para os que se dedicavam à Lectio Divina, um roteiro para o entendimento, ou tradução, de significados misteriosos contidos nos textos sagrados. Todo esse universo de mecanismos

\footnotetext{
${ }^{11}$ apud BESTUL, T. "Meditatio/Meditation". In: HOLLYWOOD, A. op.cit, p. 162.

${ }^{12}$ AGOSTINHO, S. Confissões. Porto: L.A.I., 1981, p. 359.

${ }^{13}$ MATTER, E. A. "Lectio Divina”. In: HOLLYWOOD, A. op.cit, p. 151.
} 
e entendimentos fazia parte do acervo conceitual existente nos meios religiosos católicos no limiar das grandes transformações da modernidade.

\section{Mística na modernidade}

Alguns autores reconhecem hoje na Devotio Moderna, movimento religioso que surgiu na Holanda, no século XIV, um dos principais sinais das grandes transformações que estavam em curso na espiritualidade ocidental ${ }^{14}$. Embora não seja nosso objetivo aqui tratar do assunto, cabe assinalar que uma das mais fortes características da Devotio Moderna, que deu origem tanto a movimentos institucionais quanto a heresias, foi a de consolidar uma tendência à interiorização, no âmbito da religiosidade popular, numa fase de crise do antigo movimento monacal, e de buscar propiciar uma experiência religiosa mais ampla do ponto de vista social, numa era de emergência da sociedade, ou, do ponto de vista da Igreja, dos leigos.

Ali estavam presentes todos os elementos técnicos da mística anterior, e uma das suas culminâncias literárias foi o Imitatio Christi "A Imitação de Cisto" de Tomas Kempis. O século XIV, aliás, realizando toda a importância que vinha sendo dada à humanidade de Cristo, produziu inumeráveis textos sobre a vida de Jesus, sob direta ou indireta influência da Devotio Moderna, em seu sentido mais restrito ou mais amplo. Entre tais textos encontra-se o não menos influente Vita Christi, atribuído a Ludovico da Saxônia (?-1377). Vita Christi é uma extensa coletânea de textos de diferentes origens, usualmente voltados para a experiência interior de Jesus, dentro da tradição mística medieval, mas, principalmente, dirigido às pessoas comuns ${ }^{15}$.

Todo esse universo literário e, junto com ele, todo um mundo de preocupações espirituais, começaram a se tornar evento gerador de acontecimentos na Espanha durante o século XV. A Espanha era uma região particularmente sensível às grandes questões religiosas da época. Primeiro, porque ali cristãos e muçulmanos travavam um conflito diário há séculos, que tinha implicações políticas mas também religiosas. Segundo, na Península Ibérica os conflitos entre cristãos e judeus eram milenares e tensionavam a sociedade em graus variáveis e sempre significativos. Mas, acima de tudo, o universo intelectual católico espanhol era do mais alto nível, fruto de grandes

\footnotetext{
${ }^{14}$ VAN ENGEN, J. Sister and Brothers of Common Life. Pennsylvania: University Press, 2008. ${ }^{15}$ WALSH, M.“'To always be thinking somehow about Jesus': The Prologue of Ludolph's Vita Christi”. Studies on the Spirituality of Jesuits 43/1 (2011), pp. 1-21.
} 
demandas doutrinárias e imbuído de uma percepção aguda do papel central que a Igreja desempenhava na história passada e presente da sociedade, sua identidade e seus objetivos institucionais - foi a época dos reis católicos: Fernando e Isabel.

Um grande papel foi desempenhado nesse processo pelo Cardeal Francisco Jimenez de Cisneros (1436-1517). Franciscano, homem de grande atividade e amigos, confessor da rainha, Cisneros foi provincial dos franciscanos em Castela, Arcebispo de Toledo, Inquisidor Geral, Regente do trono (duas vezes), Cardeal, Governador do reino de Castela. Dois de seus empreendimentos nos interessam particularmente: primeiro, as suas duras ações no sentido de reformar os costumes do clero espanhol, tanto regular quanto secular, e desenvolver a religiosidade católica em Espanha. De alguma forma tomado pelo espírito da Devotio Moderna, deu grande valor aos movimentos místicos, especialmente às beatas e aos outros visionários que então promoveu. Foi célebre seu apoio, por exemplo, a Maria de Santo Domingo, La Beata de Pedrahita, voltando-se acintosamente, no caso, contra a opinião dos dominicanos. Segundo, a sua dedicação a temas da cultura católica e desenvolvimento dos estudos teológicos. Dedicou-se a encomendar traduções das principais obras místicas de seu tempo, entre elas os textos de Pseudo-Boaventura, Ludovico da Saxônia e o Pseudo-Dionísio, e publicá -las em tiragens consideráveis ${ }^{16}$. No sentido do fortalecimento dos estudos religiosos, sua principal atividade foi a fundação da Universidade de Alcalá, em 1487, aberta para atividades em $1508^{17}$.

Por sua inspiração, imprimiram-se, às expensas da universidade, vários textos místicos e religiosos, em vernáculo, e, principalmente, a Bíblia Poliglota Complutense, texto fundamental para os estudos bíblicos da época, na qual constavam, lado a lado, para análise e comparação, os textos hebraico, grego e latino. Como explicou, "as palavras têm seu caráter único... estão repletas de uma variedade de sublimes verdades, que não podem ser entendidas por outra fonte que não a mensagem original..."18. Para Cisneros, a Lectio Divina, numa perspectiva catafática, passava por um aprofundamento técnico do processo de tradução. Cisneros, de fato, foi um dos responsáveis pela montagem de estruturas culturais e educacionais que favoreceram o florescer da mística

\footnotetext{
${ }^{16}$ RUMMEL, E. Jiménez de Cisneros: On the Threshold of Spain's Golden Age. Tempe: Arizona Center for Medieval and Renaissance Studies, 1999, p. 43.

${ }^{17}$ Idem, ibidem, p. 56.

${ }^{18}$ Idem, ibidem, p. 63.
} 
e do pensamento religioso na Espanha no século seguinte, mas também de um olhar mais objetivo sobre a natureza da leitura dos textos sagrados.

O grande problema da mística, no entanto, sempre fora, no fundo, aquela sombra que Santo Agostinho apontou como possível na visão espiritual: a presença do mal, ou, do ponto de vista institucional, da heresia. O significado da Devotio Moderna era a de afirmar a possibilidade de uma experiência mística mais ampla, ligada ao mundo, na qual a tradução do mistério pudesse servir para aproximar todos os homens da Verdade de Deus. Entre os séculos XIV e XVI, no entanto, pelo menos dois grandes movimentos de origem mística tinham sido identificados como heréticos: o do "Livre Espírito" e do Mestre Eckart, e o dos "Iluminados", "Alumbrados", este último na Espanha. Ambos os movimentos eram crentes na absoluta superioridade do contato com Deus, na mística, ou mesmo defendiam extravagantes teses sobre a fusão das almas com o Absoluto, mas sempre marchando na direção do desprezo pelas formas institucionais, rituais e tradicionais de culto. $\mathrm{O}$ esforço de muitos místicos era impedir que isso acontecesse, donde a necessidade de uma literatura orientadora segura, e por isso o espírito da linha editorial do Cardeal Cisneros.

\section{Conclusões: Santo Inácio, tradutor}

Iñigo era um basco cuja vida o levou a envolver-se nos conflitos militares do seu tempo. Foi ferido numa batalha cruenta, defendendo a cidade de Pamplona em 1521. Durante sua recuperação, lenta e dolorosa, chegou às suas mãos dois livros em castelhano: A Legenda Áurea que continha narrativas de vidas de santos, e o Vita Christi, de Rodolfo da Saxônia. Ambos frutos do empenho editorial do Cardeal Cisneiros, como vimos. Pelo Vita Christi leu também os Evangelhos, que só podiam então ser conhecidos através de semelhantes textos, que continham partes deles traduzidos para o vernáculo, principalmente porque Iñigo não lia latim ${ }^{19}$. Nesse período de convalescença começou a ter sentimentos fortes, e visões, da presença de Deus. Mais tarde, mais ou menos recuperado, Iñigo foi à Catalunha, ao Santuário de Montserrat, onde teve uma outra seqüência de experiências místicas. Assim, por muito tempo, rezando, "costumava ver com seus olhos interiores a humanidade de Cristo" ${ }^{20}$.

\footnotetext{
${ }^{19}$ WALSH, M. op.cit., p. 10.

${ }^{20}$ LOYOLA, S. I. “Reminiscences”. In: Personal Writings. London: Penguin, 1996, p. 26.
} 
Parece claro que Iñigo retomou aqui um fluxo ininterrupto de experiências que remontam a períodos pré-cristãos: vivenciar Deus, traduzir essa experiência para si e para o mundo. Nesse sentido, não parece que sua produção mais prática, os Exercícios, fosse entendido por ele como algo seu. Como anota Philip Endean, Santo Inácio "não prescreve diretamente o uso de seu próprio livro - ele simplesmente diz "exercícios espirituais"". ${ }^{21} \mathrm{E}$, de fato, como podemos observar, "exercícios espirituais" enquanto práticas ordenadas para conduzir o ser na direção de Deus através de suas semelhanças, pelo meio da imaginação, foram experiências frequentes na história do mundo cristão medieval, gerando textos com esse mesmo título. "Assim como passear, caminhar e correr são exercícios corporais, também se chamam exercícios espirituais os diferentes modos de a pessoa se preparar e dispor para tirar de si as afeições desordenadas", explicou Santo Inácio ${ }^{22}$. Isto é, caminhar pelo caminho ordenado, o caminho de Deus.

É necessário considerar, portanto, que os Exercícios Espirituais de Santo Inácio eram, eles mesmos, uma tradução de uma prática tradicional de exercícios do mesmo teor que vinham sendo feitos nos últimos séculos por toda cristandade. Uma tradução para aquele tempo presente, para o ambiente transformado de um mundo diferente do anterior. Observemos que o próprio Cisneros, muito místico, muito crente no poder da imaginação, desliza, no entanto, na Bíblia Complutense, para uma inovadora defesa da busca da concretude na tradução, tema por si limitador do pleno império do olhar imaginativo sobre o texto. Uma nova inflexão do Lectio Divina, que já estava, aliás, em desenvolvimento nos círculos interessados na Europa. A existência desse mundo novo de objetividades já era então evidente, e Santo Inácio traduzia o universo do divino tendo em vista essa realidade.

As reticências agostinianas sobre a imaginação, a visio spiritualis, tornavam-se muito presentes numa era em que a ascendência da sociedade à religião tornava a mística fonte permanente de heresias. Mas a crítica à predominância do olhar imaginativo não vinha apenas de dentro da Igreja, mas também de fora, fundada em outras razões: vivia-se então a ascensão vertiginosa dos raciocínios fundados em números e em quantidades. Faltava pouco, naquele momento, para a publicação do De Revolutionibus Orbium Coelestium de Nicolau Copérnico (1543), livro que consolidaria a tendência incontrolável, que

\footnotetext{
${ }^{21}$ ENDEAN, P. "The Espiritual Exercises”. In: WORCESTER, T. The Cambridge Companion to the Jesuits. Cambridge: Cambridge, 2008.

${ }^{22}$ LOYOLA, S. I. Exercícios Espirituais. São Paulo: Loyola, 1990, p. 11.
} 
tomaria corpo nas sociedades ocidentais, de substituir as qualidades subjetivas do pensamento e da imaginação pelo império das quantidades, como única fonte legítima para obter-se conhecimento do mundo.

Tal inclinação levaria, algum tempo depois, Baruch Espinosa a defender a superioridade do cristianismo sobre o judaísmo por conta do fato de Jesus receber a mensagem de Deus, mente ad mentem, mente a mente, e não através de verba et images, palavras e imagens, como Moisés ${ }^{23}$. O que é, de certa forma, bem agostiniano. Mas, por outro lado, terminou por criticar violentamente o império da imaginação, pois a entendia como fonte de confusão intelectual e epistêmica, donde a "crítica da profecia" ser, em Espinosa, para Steven Smith, "o necessário primeiro passo para a emancipação do indivíduo" 24 e daí, portanto, sua ética "à maneira dos geômetras", isto é, uma racionalidade absoluta no estudo do fenômeno humano. $\mathrm{O}$ combate à imaginação parece ser, a partir desse momento, um dos mais marcantes traços do mundo moderno e tem um de seus pontos culminantes na irônica crítica de Emmanuel Kant às visões de Emanuel Swedenborg.

Cisneros, ao defender a concretude das palavras, já exteriorizava, portanto, algum movimento de crítica à imaginação, pois sustentava, ao afirmar a necessidade de uma tradução racional, que os números, isto é, a objetividade, eram mais eficientes, em certas circunstâncias, para obter verdades sobre o mundo do que a imaginação (quantas vezes as palavras originais aparecem em tais sentidos ou contextos e quantas não, e o que se pode retirar de seu sentido original a partir disso). As qualidades começavam a se submeter aos números. É claro que, para Cisneros, essa aproximação racional era submetida à aproximação subjetiva. Mas não escapará, aos observadores atentos, que o fortalecimento excessivo desse caminho inviabilizaria, em algum momento, a legitimidade intelectual de encontrar-se com Deus, ou vivenciá-Lo misticamente. Pois, era antiga sabedoria, subjetiva, portanto, que Deus não pode ser explicado com instrumentos objetivos deste mundo.

Santo Inácio traduz toda uma tradição de exercícios e experiências místicas para o seu tempo, onde questões como essas começavam a ser dominantes na argumentação. Sem dúvida, assim, defende a interiorização, é necessário "sentir e saborear as coisas internamente" 25 e sustenta a capacidade redentora

${ }^{23}$ ESPINOSA, B. Tratado Teológico-Politico. Lisboa: IN-Casa da Moeda, 2004, p. 186. ${ }^{24}$ SMITH, S. B. Spinoza, Liberalism, and the Question of Jewish Identity. Yale: Yale University Press, 1997, p. 95.

${ }^{25}$ LOYOLA, S. I. Exercícios Espirituais. op.cit., p. 11. 
da visio spiritualis, elevando os sentidos corpóreos a um nível imaginativo, através do qual eles podem ver, ouvir, sentir o cheiro, o paladar e tocar Jesus ${ }^{26}$. Mas Santo Inácio é um tradutor, e na forma simples, fácil e breve com que expõe os seus Exercícios (para se ter uma ideia, Vita Christi, de Ludolfo da Baviera, tinha mais de duas mil páginas, o texto de Inácio em torno de cem), expressa a vivência de Deus num mundo de intensas ocupações e trabalho em tempo integral.

Mas além de traduzir todo esse universo de inspirações e visões para o mundo moderno, Santo Inácio também traduz a sua experiência neste mundo moderno. Assim, expressa sua crença na realidade da razão e de que todos os homens dela dotados, "e de bom senso, se oferecerão totalmente ao trabalho", isto é, seguirão o caminho do bom espírito, submetendo seus sentidos, "por determinação deliberada", com autonomia e liberdade, ao "vosso maior serviço e louvor"27. Ou seja, a razão e a liberdade se justificam quando trabalham na orientação do ser na direção de Deus, e não na do mundo, e quando não é contraditória à visão espiritual, mas sim um fator de discernimento.

Assim também, na sociedade de massas, e diante da multidão e de seus desejos, numericamente majoritários e poderosos, fenômeno que pela primeira vez se torna claro no século XVI e ao longo dos grandes descobrimentos, Santo Inácio traduz uma mensagem essencial: "Verei sucessivamente as pessoas. Primeiramente os homens que vivem na face da terra, tão diversos nos trajes e nas atitudes; uns brancos, outros negros; uns em paz, outros em guerra; uns chorando, outros rindo; uns com saúde, outros sem ela; uns nascendo, outros morrendo. Em segundo lugar, verei e considerarei como as Pessoas divinas, assentadas no trono de sua Divina Majestade, contemplam na vasta superfície da terra todos os povos (...) depois o que dizem as Pessoas divinas, a saber: 'Façamos a redenção do seres humanos"'28. Visualiza Santo Inácio que a sobrevivência do indivíduo no meio dessa quantidade opressiva e plural está relacionada à retenção ética a uma qualidade essencial: a presença redentora de Deus. Ela ilumina e dá sentido a um caminho que sobrevive mesmo quando imerso em um universo de fragmentações ou atomizações.

E, por fim, os números em si. Muitos pensadores do século XVI cobravam dos matemáticos a matemática. Isto é, exigiam que as contas fossem feitas corretamente e que não se desviassem da realidade das quantidades para

\footnotetext{
${ }^{26}$ Idem, ibidem, p.77.

${ }^{27}$ Idem, ibidem, pp. 66-68.

${ }^{28}$ Idem, ibidem, pp. 72-73.
} 
tentar apreensões subjetivas com o olhar da imaginação, ou mesmo o olhar intelectual, donde o gradual declínio do alquimia, da numerologia e da astrologia, nas quais os números submetiam-se a subjetividades. Copérnico fala sobre isto no prefácio de seu livro. Acreditava-se que da matemática deveria emergir um saber universal, por todos verificável. Santo Inácio, como Cisneiros, afirma sua utilidade e necessidade. No entanto, estabelece parâmetros precisos para entendê-la, como meio.

Nos seus Exercícios Espirituais, Santo Inácio propõe que o exercitante examine cuidadosamente sua consciência, primeiro pela manhã. Após fazer isso, ele deve marcar na letra que designa seu "pecado particular ou defeito"... "de que se quer corrigir e emendar" "tantos pontos quantas forem as vezes que incorreu naquele pecado particular ou defeito". Faz-se novo exame, à noite, e anota-se quantos pontos "quantas forem as vezes que incorreu naquele pecado particular ou defeito". O exame deve repetir-se no dia seguinte e nos dias posteriores "e ver se houve emenda de um dia para o outro". A seguir "compara-se uma semana com a outra e ver se se emendou na semana presente, em comparação com a semana anterior" ${ }^{29}$. Após isso, o exercitante examina suas curvas gráficas, na verdade estatísticas, das variações de seus pecados e defeitos ao longo do tempo e de seus sucessos e fracassos no caminho de Deus.

Assim, diante da matemática em processo de emergência, enquanto poder epistêmico, Santo Inácio de Loyola, tradutor das razões maiores de Deus, assinala sim a sua utilidade e caráter de portadora de verdade. Mas evocando uma percepção profunda de um universo de qualidades que estão além deste mundo e que contém um saber redentor absoluto, e ao qual só se acessa pela imaginação, pelas visões interiores, instrumentaliza as curvas estatísticas para refletir sobre qualificações subjetivas, sobre os pecados. Constrói uma estatística das subjetividades.

Num mundo que se curva diante dos números, ao dinheiro, por exemplo, abandonando de forma crescente as qualificações de ordem moral e religiosa, Santo Inácio afirma que os números devem se submeter às qualidades. Não há de fato nenhuma novidade na mensagem eterna que Deus transmite, nas visões dos profetas desde tempos antigos até a mística dos tempos mais recentes: toda a obra do homem no mundo deve reconhecer a grandeza do entendimento e da obra maior de Deus - e a ele se submeter. A realização do amor e de ações virtuosas deve ser o principal objetivo de toda verdadeira operação matemática e escopo de toda ciência humana. Profecia densa e preocupada, no

${ }^{29}$ Idem, ibidem, pp. 31-33. 
alvorecer de nosso mundo contemporâneo, tomado pela razão e crítico de toda imaginação, devaneio e visão.

$\mathrm{Na}$ inserção histórica da tradição profética, no âmbito de um permanente esforço para tornar compreensível o significado maior da Eternidade no tempo presente, Santo Inácio aponta, como profeta, os parâmetros da tradução mística no mundo contemporâneo. Estabelece as bases de uma individualidade temente a Deus repleta de Espírito, de uma racionalidade voltada à Redenção e à fonte da vida e um projeto de subjetividade que contêm a quantificação, mas cuja essência e sentido só pode ser depreendida numa dimensão maior, localizada no interior do mistério de Deus.

\section{Referências bibliográficas}

AGOSTINHO, S. Confissões. Porto: L.A.I., 1981.

AQUINO, S. T. Summa Contra Gentiles, Vol. I. Madrid: BAC, 2007.

AQUINO, S. T. Summa Teologica, vol. I. Madrid: BAC, 1959.

BESTUL, T. "Meditatio/Meditation". In: HOLLYWOOD, A. The Cambridge Companion to Christian Mysticism. Cambridge: Cambridge, 2012.

BONAVENTURE. "The Journey of the Mind to God". In: PETRY, A. Late Medieval Mysticism. Louisville: Westminster John Knox Press, 2006.

BURTON-CHRISTIE, D. "Early Monasticism”. In: HOLLYWOOD, A. The Cambridge Companion to Christian Mysticism. Cambridge: Cambridge, 2012.

CERTEAU, M. La fable mistique,1 XVIe-XVIIe siécle. Paris: Gallimard, 1982.

ENDEAN, P. "The Espiritual Exercises". In: WORCESTER, T. The Cambridge Companion to the Jesuits. Cambridge: Cambridge, 2008.

ESPINOSA, B. Tratado Teológico-Político. Lisboa: IN-Casa da Moeda, 2004.

FRAETERS, V. "Visio/Vision". In: HOLLYWOOD, A. The Cambridge Companion to Christian Mysticism. Cambridge: Cambridge, 2012.

LOYOLA, S. I. "Reminiscences". In: Personal Writings. London: Penguin, 1996.

LOYOLA, S. I. Exercícios Espirituais. São Paulo: Loyola, 1990. 
LOUTH, A. "Apophatic and Cataphatic Theology". In: HOLLYWOOD, A. The Cambridge Companion to Christian Mysticism. Cambridge: Cambridge, 2012.

MATTER, E. A. "Lectio Divina". In: HOLLYWOOD, A. The Cambridge Companion to Christian Mysticism. Cambridge: Cambridge, 2012.

PSEUDO-DINONYSIUS. "The Mystical Theology": 3. In: The Complete Works. New York: Paulist Press, 1987.

ROREM, P. Pseudo-Dionysius: A Commentary on the Texts and an Introduction to Their Influence. Oxford: Oxford, 1993.

RUMMEL, E. Jiménez de Cisneros: On the Threshold of Spain's Golden Age. Tempe: Arizona Center for Medieval and Renaissance Studies, 1999.

SMITH, S. B. Spinoza, Liberalism, and the Question of Jewish Identity. Yale: Yale University Press, 1997.

VAN ENGEN, J. Sister and Brothers of Common Life. Pennsylvania: University Press, 2008.

WALSH, M.“To always be thinking somehow about Jesus': The Prologue of Ludolph's Vita Christi”. Studies on the Spirituality of Jesuits 43/1 (2011), pp. 1-21.

WOLLO, L.Z.: "St Augustine on the Soul's Divine Experience": Visio intellectualis and Imago Dei from Book XII of De genesi ad litteram libri XII. Studia Patristica, vol. LXX. Leuven: Peeters, 2013.

\section{Edgard Leite Ferreira Neto}

Doutor em História pela Universidade Federal Fluminense Professor Associado Universidade do Estado do Rio de Janeiro Professor Adjunto IV Universidade Federal do Estado do Rio de Janeiro Rio de Janeiro / RJ - Brasil E-mail: edleiteneto@yahoo.com.br

Recebido em: 27/10/15

Aprovado em: 27/02/16 